\title{
Collaborative airline revenue sharing game with grey demand data
}

\author{
Mehmet Onur Olgun ${ }^{1}$
}

Accepted: 12 October 2021 / Published online: 30 October 2021

(c) The Author(s), under exclusive licence to Springer-Verlag GmbH Germany, part of Springer Nature 2021

\begin{abstract}
Airline alliances provide more flights, include different destinations, and maximize revenues. In an alliance, collaborating airlines can offer tickets for an identical flight plan, unlike the traditional single airline approach. In particular, due to epidemic/pandemic events, such as COVID-19, the available customer demands become highly uncertain across many real airline alliance problems, and maintaining stable revenue is as important as maximizing the revenue in the alliance. A critical question is how the independent airline companies of an alliance should collaborate to maintain reliable maximum revenue. Therefore, this question was studied using a grey mathematical programming model for small-sized airline alliances under grey demand data. Some cooperative game theoretical solution concepts, such as Shapley, equal revenue, Nucleolus, and minimax core, are presented. A numerical study of a small-sized alliance with three airline companies was used to interpret the results of the cooperative game theory concepts. Three cases were considered based on the grey passenger demand structure of airline collaborations to share extra revenues and maintain stable revenue distribution that would maximize the expected revenue. Based on the obtained results, the synergy of collaboration increased with the increase in the size coalition in all of the cases, except for the cases of lower (L) and upper (U) demand levels.
\end{abstract}

Keywords Airline alliance $\cdot$ Revenue sharing $\cdot$ Cooperative game theory $\cdot$ Grey mathematical programming

\section{Introduction}

An airline alliance is defined as an aviation regulation between two or more airline companies, making a collaboration on a substantial resource. Airline alliances

$凶 \quad$ Mehmet Onur Olgun

onurolgun@sdu.edu.tr

1 Faculty of Engineering, Industrial Engineering Department, Süleyman Demirel University, 32260 Isparta, Turkey 
are extensively considered in today's world with the advantage of sharing resources (e.g., sharing technology, maintenance facilities, check-in counters, code sharing, etc.). By 2015, three large-sized global airline alliances (Star Alliance, Sky Team, and Oneworld) had connecting flights that covered approximately $62.2 \%$ of the world. Alliances can collaborate to increase their revenues. Furthermore, alliances can benefit from a stronger presence in the market, more extensive level of knowledge and experience, and efficient use of their resources. Therefore, one of the major benefits is an increase in network coverage. Through a collaboration, an airline company can sell tickets for different destinations that are not covered by its fleet, but through the fleets of other airline companies. Thus, an increase in network coverage can help the airline to become more competitive and attract more air traffic as well as revenue.

In order to optimize revenue, the airline revenue management evaluates which products/fare classes to make available for sale throughout the booking period. However, the effects of such unexpected cases may mislead decision makers. Consequently, uncertainty in decision making is a considerable issue in today's competitive world. For instance, the effect of the COVID-19 pandemic on the airline industry has been considerable. The International Air Transport Association (IATA) has estimated revenue losses for global passenger airlines of up to USD $\$ 113$ billion. In the supply chain that serves the airline industry, the effects are projected to have a ripple effect. In unexpected cases, the exact values of decision variables, such as passenger demand, price of flight products, and capacity, which may consist of uncertain parameters, have been addressed. Such unexpected cases may result due to various sources of fluctuations in passenger demand data, epidemics/pandemics, politics, natural disasters, war, and so on. Mostly, uncertainties have been studied using the probability theory in stochastic game theory. The model parameters are given random variables with a specific probability distribution in a probabilistic approach. However, due to a lack of previous data, it is not possible to determine the exact probability distributions. Fuzzy game theory approaches are mostly used to deal with the problem with vague numbers (Mallozzi et al. 2011). However, it is hard to define the fuzzy membership functions in real life problems. Therefore, in this study, the grey passenger demand parameters and grey mathematical programming approach were used.

In this study, a new grey mathematical programming (GMP) model was proposed for a collaborative revenue sharing problem with a small-sized airline alliance. In the grey mathematical model used for collaboration in the airline alliance problem, each of the airline companies are considered as a player in a game. The advantages of the collaboration of the airline companies was investigated herein. The synergy resulting from an alliance is known to increase revenue. Furthermore, various cooperative game theory methods were suggested for fair sharing of the collaborating airlines revenue between the airline companies. Hence, it was especially aimed to focus on the following research questions in this study:

- How can the revenues of airline companies from different flights (products) in an airline alliance be evaluated?

- How are the revenues of airline companies affected by airline alliance?

- How can additional revenues of airline alliance be fairly shared between collaborating airline companies? 
By answering the above questions, this paper mainly has the following contributions:

First, a grey mathematical model was defined for calculating the collaborations in small-sized airline alliance; second, the additional revenue and synergy of the collaboration were evaluated; and third, various cooperative game theory solution methods, including the Shapley value, Equal Revenue Method, Nucleolus, and Minimax Core, were used for fair revenue sharing. Moreover, to the best of our knowledge, no work has been done about practicing cooperative game theory for collaboration in an airline alliance using grey passenger demand data.

The rest of the paper is organized as follows. The related literature is reviewed in Sect. 2. Section 3 provides some preliminaries about grey numbers and the whitenization process. Then, Sect. 4 introduces a GMP model for collaboration in the airline alliance. Moreover, a numerical example is solved for small-sized airline alliance. Section 5 deals with the collaborative frameworks between the airlines in the developed grey airline alliance game. Finally, Sect. 6 summarizes the study with some conclusions and directions for future research.

\section{Related work}

This study mainly dealt with two broad literature streams: revenue sharing for noncooperative game theory and cooperative game theoretical applications. Therefore, a full review of the literature on these topics is provided in the following sections.

\subsection{Non-cooperative game theoretical applications in revenue sharing}

Netessine and Sumsky (2005) studied the seat inventory control problem using noncooperative game theory. They presented a Nash equilibrium in airline revenue management games. Moreover, they evaluated the total number of seats available in each fare category, analyzed with non-cooperative game theory methods. Saraswati and Hanaoka (2014) explored employed multi-airport multi-airline non-cooperative games with a network model in order to analyze the revenue sharing effects in various airline network settings. Their results showed that an airport prefers to share its revenue with its dominant airline in order to gain optimal benefit. Graueberger and Kimms (2016) proposed a model to maximize a competitor's revenue in an airline alliance. They studied two types of competition, namely horizontal competition and vertical competition. Moreover, they performed a computational study indicating their algorithm, which was also satisfied for computing a Nash equilibrium considering both types of competition. Gu and Zhu (2017) analyzed a model to effectively distribute the seat capacities of airline alliances in order to maximum their revenue. Accordingly, they performed a combinatorial auction model to maximize the seat allocation. Furthermore, they proposed the airline alliance as the auctioneer and seat capacity in a flight plan as lots. Nerja (2017) examined the types of vertical agreement approaches and concession revenue sharing contracts to determine how the vertical structures of airline alliances compete for passengers when they share resources. Liu et al. (2017) 
proposed a mixed integer programming model to maximize the total revenue of airline alliances by mathematical optimization with non-cooperation. They also studied both horizontal and vertical competition in airline alliances. Their results showed that airports have incentives to share the total concession revenues and that parallel alliances may improve social welfare. Li et al. (2016) developed the idea of callable products to the capacity allocation game involving duopolistic airlines. They examined the effects of the introduction of callable goods on the revenues, as well as the booking limitations of the two airlines. Sur et al. (2019) investigated revenue sharing using the Stackelberg model between platform and service providers. They explained the closed form of the maximum revenue sharing proportions as the equilibrium of the Stackelberg model. Their findings showed that potential demand was the most considerable factor in affecting maximum revenue sharing. Zhang et al. (2019) studied how to effectively coordinate an e-commerce logistics system that consisted of two horizontal carriers considering the impact of the logistics service level using the Cournot game and Stackelberg game model. They proved the effectiveness of horizontal carrier collaboration and explicated the reason for the lower marginal profit in the logistics theoretically. Sorouri et al. (2019) proposed a framework to be used for the analysis of the cooperation of competing airlines using the multi-criteria game theory model. To apply the results of the model, three competitor airlines were selected on an Iranian domestic flight. Levi et al. (2020) studied resource sharing in joint ventures under demand uncertainties. They examined a non-cooperative game theoretical approach considering two types of joint ventures depending on how individual resources determine the adequate capacity of a joint venture. Furthermore, they showed that multiple Nash equilibria could exist. Seo (2020) conducted a review of substantial competitive advantages through an international alliance.

\subsection{Cooperative game theoretical applications in revenue sharing}

Krajewska et al. (2008) combined the features of cooperative game theory and routing problems and explored the profit margins resulting from horizontal cooperation among freight carriers and also used the Shapley value to determine a fair allocation. Agarwal et al. (2009) analyzed collaboration behaviors in transporting cargo alliances and suggested a revenue sharing mechanism to share revenues in a stable manner and determine alliance membership rules so that the continuity of the collaboration was guaranteed.

Houghtalen et al. (2011) suggested a mechanism that would use capacity exchange prices to achieve optimum utilization of the alliance capacity as well as a viable distribution of the alliance revenues. Kimms and Cetiner (2012) examined airline alliance as a game that was combined and revealed that the center of the core game was not empty and proposed a revenue sharing plan based on the Nucleolus concept. Their findings revealed that the revenue sharing could adequately be evaluated for airline alliances.

Hu et al. (2013) suggested a two-stage game that comprised hybrid model combining the cooperative and the noncooperative game approaches. In the first stage, they used a cooperative game framework to model the output of the negotiation, in which 
the airlines determined a revenue sharing rule that they would use to distribute the revenue of the interline and codeshare itineraries. In the second stage of the game, they studied efficiency by modeling the operation of the alliance as a noncooperative game in a decentralized network. Each airline controlled its own reservation system so as to maximize its expected revenue. Cetiner and Kimms (2013) suggested a model to quantify the fairness of revenue sharing methods in airline alliance that depend on the transfer of dual prices and assessed the fairness of the new mechanism using cooperative game theoretical methods. Wright (2014) proposed a revenue sharing method to solve revenue management problems for different flight plans under the incomplete information and analyzed the performance of their method by comparing it with a centralized controller in sample alliances. Liu et al. (2014) suggested a strategy to analyze alliance revenue distribution using the game theory. They studied revenue distribution and flight frequency with both non-cooperative and cooperative games before and after an alliance from the perspective of maximizing flight frequency. Wen (2017) studied a number of models to assess the decision-making mechanisms of the airline cargo alliance and evaluate relevant flight schedules under cargo alliances. A fuzzy cooperative game was developed to assess the combination of alternatives to the airline cargo alliance. Each alternative alliance was defined as a coalition of the units of decision, and its characteristic function was estimated using fuzzy interval values. Chung et al. (2018) used a collaborative approach to increase the competitiveness of courier service companies, in which a nucleolus-based revenue sharing method was used for fair sharing of the revenues to each joining company based on a cooperative game theory. An et al. (2019) integrated cooperative game theory with network data envelopment analysis (DEA) to examine the revenue-sharing problem in a three-stage system. They designed network DEA models to quantify the system's maximum revenues. Moreover, they used the Shapley value method to share the revenues of the system to its stages. Their results showed that the game among steps in a three-stage order is super additive. Wang (2020) investigated an axiomatic approach and considered the maximum revenue problem for the airline alliances, and suggested a simple sharing rule that distributed the revenue of each flight equally among the carriers of the flight. The study also revealed that the rule coincided with the Shapley value of the game associated with the problem. Furthermore, there is some important research in the literature that used grey system models to design network airline routes, determine flight frequencies on individual routes, and forecast airline passenger demand (e.g., Hsu and Wen 2000; Benitez et al. 2013). Table 1 presents a summary of the literature regarding different demand and problem types, and the solution methods, and compares the problems existing in the literature with the problem suggested in this research.

\section{Preliminaries: grey number and whitenization process for grey demand data}

The grey system theory was introduced by Deng in early 1982 and it quickly developed in fields ranging from engineering to social sciences. The grey system theory is performed on small data and insufficient information and is classified according to 
Table 1 Summary of the literature regarding alliances and its different variants

\begin{tabular}{|c|c|c|c|c|}
\hline References & Alliance type & Demand type & Main purpose & Solution methods \\
\hline $\begin{array}{l}\text { Krajewska et al. } \\
\text { (2008) }\end{array}$ & Freight carriers & & $\begin{array}{l}\text { Higher profit } \\
\text { allocation }\end{array}$ & $\begin{array}{l}\text { Cooperative game } \\
\text { theoretic }\end{array}$ \\
\hline $\begin{array}{l}\text { Agarwal et al. } \\
\text { (2009) }\end{array}$ & $\begin{array}{l}\text { Airline and sea } \\
\text { Cargo Shipping }\end{array}$ & & $\begin{array}{l}\text { Reducing } \\
\text { transportation } \\
\text { cost }\end{array}$ & $\begin{array}{l}\text { Designing sharing } \\
\text { mechanisms }\end{array}$ \\
\hline $\begin{array}{l}\text { Houghtalen et al. } \\
\text { (2011) }\end{array}$ & Cargo Carriers & Probabilistic & $\begin{array}{l}\text { Higher profit } \\
\text { allocation }\end{array}$ & $\begin{array}{l}\text { Designing sharing } \\
\text { mechanisms }\end{array}$ \\
\hline $\begin{array}{l}\text { Kimms and } \\
\text { Cetiner (2012) }\end{array}$ & Airline & Deterministic & $\begin{array}{l}\text { Higher revenue } \\
\text { sharing }\end{array}$ & $\begin{array}{l}\text { Nucleolus based } \\
\text { cooperative } \\
\text { sharing } \\
\text { mechanism }\end{array}$ \\
\hline $\begin{array}{l}\text { Cetiner and } \\
\text { Kimms (2013) }\end{array}$ & Airline & Determinstic & $\begin{array}{l}\text { Higher revenue } \\
\text { Sharing }\end{array}$ & $\begin{array}{l}\text { Fair cooperative } \\
\text { game theoretic } \\
\text { sharing } \\
\text { mechanism }\end{array}$ \\
\hline Hu et al. (2013) & Airline & & $\begin{array}{l}\text { Higher revenue } \\
\text { Sharing }\end{array}$ & $\begin{array}{l}\text { Non-cooperative } \\
\text { and cooperative } \\
\text { game theoretic }\end{array}$ \\
\hline Wright (2014) & Airline & & $\begin{array}{l}\text { Higher revenue } \\
\text { sharing }\end{array}$ & $\begin{array}{l}\text { Bid-Price } \\
\text { approach }\end{array}$ \\
\hline Liu et al. (2014) & Airline & & $\begin{array}{l}\text { Maximizing } \\
\text { flight } \\
\text { frequency }\end{array}$ & $\begin{array}{l}\text { Non-cooperative } \\
\text { and cooperative } \\
\text { game theoretic }\end{array}$ \\
\hline $\begin{array}{l}\text { Saraswati and } \\
\text { Hanaoka } \\
(2014)\end{array}$ & Airline & & $\begin{array}{l}\text { Higher revenue } \\
\text { Sharing }\end{array}$ & $\begin{array}{l}\text { Non-cooperative } \\
\text { game theoretic }\end{array}$ \\
\hline Wen (2017) & Airline Cargo & Fuzzy & $\begin{array}{l}\text { Higher revenue } \\
\text { sharing }\end{array}$ & $\begin{array}{l}\text { Coperative fuzzy } \\
\text { game theoretic }\end{array}$ \\
\hline $\begin{array}{l}\text { Chung et al. } \\
\text { (2018) }\end{array}$ & Airline & & $\begin{array}{l}\text { Higher revenue } \\
\text { sharing }\end{array}$ & $\begin{array}{l}\text { Nucleolus based } \\
\text { cooperative } \\
\text { sharing } \\
\text { mechanism }\end{array}$ \\
\hline An et al. (2019) & $\begin{array}{l}\text { Network data } \\
\text { envelopment }\end{array}$ & & $\begin{array}{l}\text { Higher revenue } \\
\text { sharing }\end{array}$ & $\begin{array}{l}\text { Shapley based } \\
\text { cooperative } \\
\text { sharing } \\
\text { mechanism }\end{array}$ \\
\hline $\begin{array}{l}\text { Sorouri et al. } \\
\text { (2019) }\end{array}$ & Airline & & $\begin{array}{l}\text { Higher revenue } \\
\text { Sharing }\end{array}$ & $\begin{array}{l}\text { Non-cooperative } \\
\text { multi-criteria } \\
\text { game theoretic }\end{array}$ \\
\hline $\begin{array}{l}\text { Zhang et al. } \\
\text { (2019) }\end{array}$ & $\begin{array}{l}\text { E-commerce } \\
\text { logistics carriers }\end{array}$ & & $\begin{array}{l}\text { Higher revenue } \\
\text { Sharing }\end{array}$ & $\begin{array}{l}\text { Non-cooperative } \\
\text { game theoretic }\end{array}$ \\
\hline Levi et al. (2020) & Joint Venture & Uncertain demand & $\begin{array}{l}\text { Higher resource } \\
\text { sharing }\end{array}$ & $\begin{array}{l}\text { Non-cooperative } \\
\text { game theoretic }\end{array}$ \\
\hline Wang (2020) & Airline & & $\begin{array}{l}\text { Higher revenue } \\
\text { sharing }\end{array}$ & $\begin{array}{l}\text { Designing sharing } \\
\text { mechanisms }\end{array}$ \\
\hline This research & Airline & $\begin{array}{l}\text { Uncertain grey } \\
\text { demand }\end{array}$ & $\begin{array}{l}\text { Higher revenue } \\
\text { sharing }\end{array}$ & $\begin{array}{l}\text { Cooperative game } \\
\text { theoretic }\end{array}$ \\
\hline
\end{tabular}


the 'colors' of systems, wherein black shows unknown information and white shows known information, while grey describes information that is partially known (Julong 1989; Liu et al. 2010).

In this section, some mathematical definitions from the grey number and whitenization value of a grey number are given for a cooperative GMP model. Thus, grey numbers were determined.

A number with both a lower limit $\underline{a}$ and an upper limit $\bar{a}$ is called a grey number. This is also true if the exact value is vague, but a range within that the value lies is known. In scientific works, grey numbers are mostly observed in fields ranging from engineering to social sciences. A grey number is illustrated as $\otimes \in[\underline{a}, \bar{a}]$ (Alparslan Gök et al. 2018; Joanna et al. 2020).

When the distribution of an grey number is unknown, the equal-weight mean whitenization is often employed. Thus, the whitenization value for a grey number is obtained by taking the value of $\alpha$ as $\frac{1}{2}$. This value is known as the equal weight mean whitenization value.

The whitenization value of a grey number $\otimes \in[a, b]$ is denoted by $\tilde{\otimes}$ and is defined by $\tilde{\otimes}=\alpha a+(1-\alpha) b, \alpha \in[0,1]$.

When the distribution of a grey number is known, it is natural to take such a whitenization that is generally not equal-weight. For example, A certain airline's passenger demand is possibly between 80 and 100 . Hence, $\otimes \in[80,100]$ is the grey number. What is also known is that the passenger demand is in the interval from 90 to 95 during busy seasons based on historical data. For this grey number, it will not be reasonable for us to employ equal-weight whitenization. Hence, it is known that there is a higher probability that there will be a passenger demand that is between 90 and 95. However, there is no historical data regarding unexpected circumstances, such as epidemic/pandemic events. Generally speaking, the whitenization weight function of a grey number is designed according to what is known to the researcher. Thus, the equal weight mean whitenization value method for the whitenizing process of grey demand data is used for airlines.

\section{Grey mathematical programming formulation for collaboration in airline alliance}

Airline alliances are collaborations in which two or more airline companies combine all or part of their networks by sharing their services. Accordingly, they may provide flights between extra origin destination (OD) pairs and higher capacity flights. A product in the airline industry refers to a flight with a particular fare class between an OD pair. Moreover, the demand for incoming flights at the collaborating airlines is also pooled.

In this study, a GMP model for the airline alliances was developed. The following assumptions present the scope of this research for the airline alliance mathematical programming formulation based on grey demand data.

1. There are $N$ airlines in a network with rational behavior. They can collaborate and build an alliance that comprises the flight legs. 
2. The OD flight options provided by the alliance and the related prices are considered to advance.

3. There are two resource constraints, such as the flight leg capacity and passenger demand. Airlines can share them with each other in a coalition.

4. It is known that the demands of the OD fights are independent in such a way that it is not permitted to switch customers between price classes. Moreover, passenger demand is not known precisely, and is handled as grey demand data. The rest of the parameters, except for demand data, are considered deterministic.

5. A basic principle of the cooperative game theory is transferable utility (TU) games; hence, the capacities or demands, obtained from the collaboration, are transferable.

6. The GMP aims to maximize the expected revenue of collaboration, and obtain the number of seats to be distributed to each OD flight.

A set of indices, parameters, and decision variables is used in the GMP formulation, which is introduced as follows:

$i$ the set of airlines,

$j$ the set of flight legs of the alliance,

$l$ the set of products of the alliance,

$f_{j}$ the price of the product $j$,

$a_{l j}$ the resource coefficient of flight leg $l$ to the product $j$,

$Q_{i l}$ the possible seat capacity of airline $i$ to product $l$,

$\otimes_{i j}$ the grey demand of product $j$ arriving to the airline $i$,

$Y_{j}$ the number of seats distributed to the product $j$.

Basically, the main objective in the alliance is maximizing airlines revenue in the alliance. Furthermore, obtaining the number of seats distributed to the OD flight (ODF) $i$ using a grey-based collaborative game model will be explained. Therefore, this section discusses mathematical programming based on grey demand data for each possible collaboration between airlines. The grey collaborative game model for airlines is defined as follows:

$$
\begin{aligned}
& w(R)=\operatorname{maximize} \sum_{j=1}^{m} f_{j} Y_{j} \\
& \text { subject to } \\
& Y_{j} \leq \sum_{i \in S} Q_{i l} l=1, \ldots, n \\
& Y_{j} \leq \sum_{i \in S} \otimes_{i j} \quad j=1, \ldots, m \\
& Y_{j} \geq 0 \quad j=1, \ldots, m .
\end{aligned}
$$

Let the set $N=\{1,2, \ldots, i, \ldots, n\}$ indicate the set of airlines. The airlines are also called players, and these terms may be used identically throughout the study. A collaboration of airlines may cooperatively share resources, such as available seat capacities and revenues. A set of $S \subseteq N$ indicates a coalition of airlines that plan to collaborate. The essential aim of the model is to maximize the total revenue of airline 
alliance over all of the products. Constraint (2) expresses the capacity restrictions of the flight legs. Constraint (3) ensures that the number of seats distributed for each ODF is smaller than the sum of the demand incoming to the airlines in the alliance. Constraint (4) guarantees the non-negativity of the distributed number of seats.

Due to epidemic/pandemic events such as COVID-19, the available customer demands become highly uncertain across many real airline alliance problems. In particular, according to the social distance rules introduced after the epidemic/pandemic, airlines may enter a situation to reduce their available seat capacity. The airlines have to make collaborative decisions based on estimation of their customer demands. The aim of optimization of the grey-based approach is to maximize total revenue at an acceptable level. Then, by solving the model, the value objective function value is realized, and the values of the game in different collaborations are evaluated.

All typical mathematical programming packages, such as Gams or Gurobi software, can be used to solve this mathematical programming model. First, the main idea is to solve this model by considering the alliance of each airline separately. Then, the model of all coalitions of two airlines must be solved. In the following step, all coalitions of three airlines should be analyzed and this procedure continues until the grand coalition is obtained. Based on the super additive property of cooperative games, the revenue of the alliance for any coalitional condition must be higher than the sum of revenues of the coalition members. This property is mathematically demonstrated as:

$$
w(R) \geq \sum_{i \subset S} w\left(r_{i}\right), \quad \forall i \in N
$$

Indeed, the difference between the coalitional maximum revenue and the sum of the separate maximum revenue indicates the extra revenue $E R_{R}$ formed by the coalition, which can be expressed as:

$$
E R(R)=w(\mathrm{R})-\sum_{i \subset S} w\left(r_{i}\right), \quad \forall \mathrm{i} \in N
$$

The extra revenue of a coalition may be described regarding the revenue of that coalition. Thus, the following basis is a more reliable measure for the synergy of a coalition and a higher synergy value indicates that the members of an alliance generate greater extra revenue.

$$
\text { Synergy }(w(\mathrm{R}))=\frac{E R(R)}{w\left(r_{i}\right)}
$$

A numerical example was used to evaluate and quantify the synergy among airlines in different cases with lower demand, whitenezed demand, and upper demand. Moreover, the grey demand data inspired by the study of Cetiner et al. (2013) was generated. Table 2 demonstrates the $\otimes_{1}, \otimes_{2}$, and $\otimes_{3}$, which are grey demands incoming by the passengers, and flight legs, fare classes, and flight prices, respectively.

In this table, the flight leg is described as the operated flights of different airlines in the alliance. For instance, any of the alliance's products include a flight from A to C 
Table 2 Flight legs, fare classes, flight prices, and grey passenger demand data for the numerical example

\begin{tabular}{lllllll}
\hline$j$ & OD & Fare Class & $f_{j}$ & \multicolumn{2}{l}{ Grey demand to airlines } \\
\cline { 5 - 6 } & & & $i=\otimes_{1}$ & $i=\otimes_{2}$ & $i=\otimes_{3}$ \\
\hline 1 & AB & 2 & 75 & {$[34,50]$} & {$[4,6]$} & {$[4,6]$} \\
2 & & 1 & 100 & {$[12,16]$} & {$[1,3]$} & {$[1,3]$} \\
3 & AC & 2 & 140 & {$[11,17]$} & {$[11,17]$} & {$[1,3]$} \\
4 & & 1 & 210 & {$[4,6]$} & {$[4,6]$} & {$[1,3]$} \\
5 & AD & 2 & 240 & {$[10,16]$} & {$[10,16]$} & {$[10,16]$} \\
6 & & 1 & 800 & {$[2,4]$} & {$[2,4]$} & {$[2,4]$} \\
7 & BC & 2 & 150 & {$[1,3]$} & {$[12,14]$} & {$[1,3]$} \\
8 & & 1 & 170 & {$[3,5]$} & {$[13,17]$} & {$[13,17]$} \\
9 & BD & 2 & 200 & {$[0,2]$} & {$[2,4]$} & {$[2,4]$} \\
10 & & 1 & 90 & {$[4,8]$} & {$[4,8]$} & {$[35,50]$} \\
11 & CD & 2 & 100 & {$[2,6]$} & {$[2,6]$} & {$[12,16]$} \\
12 & & 1 & & & & {$[7,11]$} \\
\hline
\end{tabular}

with a single stop in B. Other airlines run the flight between A and B, while separate airlines run the flight leg between B and C (see Fig. 1). Moreover, the fare class and their prices are a very basic tool in airline revenue management, which control the amount and price of the seats for sale on a given flight. Usually, fare classes have many different categories that define the benefits associated with a certain product and are also used to obtain upgrade and standby priorities. In general, higher fares are converted into better fare classes with better advantages, and higher priority and flexibilities. In this research, two fare classes were used, which were fare classes 1 and 2, respectively.

Moreover, the possible seat capacities of the airlines on each flight leg and the resource coefficient of flight legs to the airlines are given in Tables 3 and 4, respectively.

The airlines in this alliance aim to arrange their available seat capacity to increase their revenues. In this example, an examination is made to determine how the collaboration between the airlines of the alliance may yield extra revenue for them. The collaborative GMP model (1)-(4) was solved 21 times, so that for each demand level of the lower (L), whitenezed (W), upper (U), and all possible coalition values, $\{i\}:\{1\},\{2\},\{3\},\{1,2\},\{1,3\},\{2,3\},\{1,2,3\}$, the revenue of alliance $w\{i\}$ and the

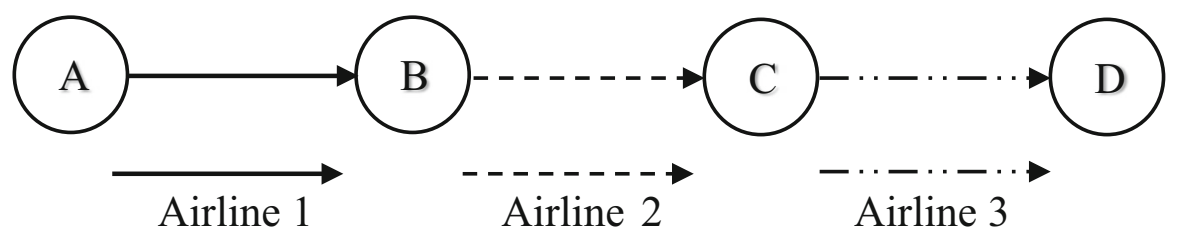

Fig. 1 Alliance network with three airlines for the numerical example 
Table 3 Capacity values for the numeric example

\begin{tabular}{llll}
\hline$l$ & & & \\
\hline$C_{i l}$ & $\mathrm{AB}$ & $\mathrm{BC}$ & $\mathrm{CD}$ \\
$i=1$ & 60 & 0 & 0 \\
$i=2$ & 0 & 40 & 0 \\
$i=3$ & 0 & 0 & 60
\end{tabular}

corresponding extra revenue, as well as synergy values, could be evaluated. The results are illustrated in Table 5.

Table 5 shows that when the airlines operated alone, the extra revenue and synergies were zero. For the different coalitions, the airline contributions to the collaboration were not equal. When we look at case $\mathrm{W}$, where airlines 1 and 3 had lower synergy together (i.e. 0.06) in comparison to case W, in airlines 1 and 2 (i.e. 0.11). Airlines 1 and 3 produced lower synergy (0.06) when compared to airlines 1 and $2(0.11)$. These differences depended on the effectiveness of the airline companies, in addition to the airlines of the alliance for their members.

Table 5 also indicates that the transferable utility game (TU game) between the airlines was super additive with regard to case W. Additional revenues accrued as the size of the coalition increased, with the grand coalitions ( $w\{1,2,3\})$ having the largest extra income.

For case $\mathrm{L}$ for airlines 1 and $3 \mathrm{w}\{1,3\}=12405$ is between airline $2, \mathrm{w}\{2\}=4040$, $\mathrm{w}\{1,2,3\}=15535<\mathrm{w}\{1,3\}+\mathrm{w}\{2\}=16445$.

Similarly, for case $U$ for airlines 1 and $3 \mathrm{w}\{1,3\}=14055$ is between airline 2, $\mathrm{w}\{2\}=4180, \mathrm{w}\{1,2,3\}=16430<\mathrm{w}\{1,3\}+\mathrm{w}\{2\}=18235$.

Hence, the game is not supper-additive in $\mathrm{L}$ and $\mathrm{U}$.

\section{Collaborative frameworks}

While the revenue, extra revenue, and synergy were evaluated for all of the coalitions of the airlines, the difficult issue was solving the problem of 'how to share the revenues of the collaboration among the different airlines?' It cannot be an easy problem because the coalitional contributions of each airline in the alliance cannot be exactly simple. Therefore, a theoretically grounded solution background was given to examine this question. In this context, the cooperative game theory has one of the most appropriate and well-known solution techniques (Frisk et al. 2010; Hafezalkotob and Makui 2015; Hafezalkotob et al. 2018, 2019). Even though there are some cooperative game theory solution concepts, the Shapley value, equal revenue method (ERM), Nucleolus, and minimax Core methods were used. Now, some necessary cooperative game theoretical concepts will be reviewed.

As was defined in the previous part of this research, for players set $N=$ $\{1,2, \ldots, i, \ldots, n\}, w(N)$ represents that the existing revenue, while all of the players collaborate with each other. Let $z_{i}$ indicate a real number for each player $i=\{1,2, \ldots, n\}$, where $\sum_{i=1}^{n} z_{i} \leq w(N)$. The vector $\vec{z}=\left(z_{1}, z_{2}, \ldots, z_{n}\right)$ 


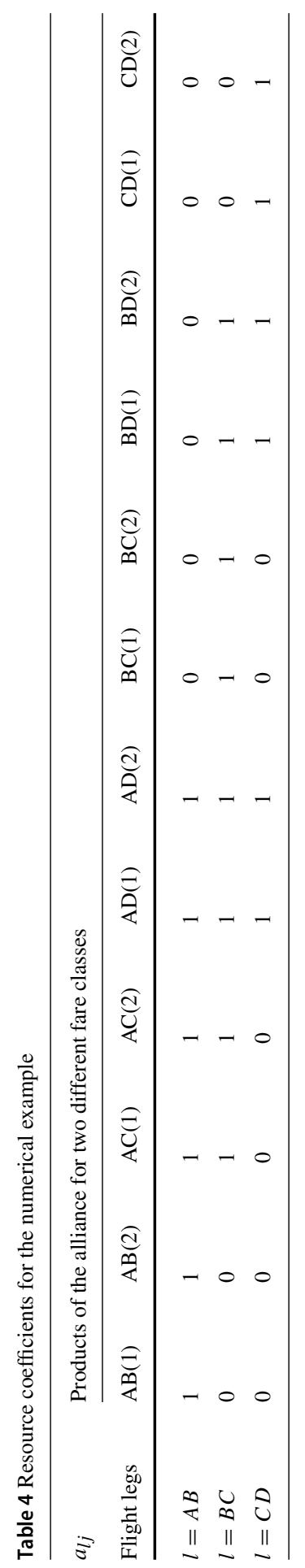


Table 5 Optimal results of the different GMP models for each possible coalition

\begin{tabular}{|c|c|c|c|c|}
\hline & Coalition & Coalition Value & Extra Revenue (ER) & Synergy \\
\hline \multirow[t]{7}{*}{$\mathrm{L}$} & $\mathrm{w}(\{1\})$ & 4350 & 0 & 0 \\
\hline & $\mathrm{w}(\{2\})$ & 4040 & 0 & 0 \\
\hline & $\mathrm{w}(\{3\})$ & 4350 & 0 & 0 \\
\hline & $\mathrm{w}(\{1,2\})$ & 9360 & 970 & 0.10 \\
\hline & $\mathrm{w}(\{1,3\})$ & 12,405 & 3705 & 0.30 \\
\hline & $\mathrm{w}(\{2,3\})$ & 9770 & 1380 & 0.14 \\
\hline & $\mathrm{w}(\{1,2,3\})$ & 15,535 & 2795 & 0.18 \\
\hline \multirow[t]{7}{*}{ W } & $\mathrm{w}(\{1\})$ & 4550 & 0 & 0 \\
\hline & $\mathrm{w}(\{2\})$ & 4110 & 0 & 0 \\
\hline & $\mathrm{w}(\{3\})$ & 5270 & 0 & 0 \\
\hline & $\mathrm{w}(\{1,2\})$ & 9700 & 1040 & 0.11 \\
\hline & $\mathrm{w}(\{1,3\})$ & 10,480 & 660 & 0.06 \\
\hline & $\mathrm{w}(\{2,3\})$ & 10,010 & 630 & 0.06 \\
\hline & $\mathrm{w}(\{1,2,3\})$ & 16,175 & 2245 & 0.14 \\
\hline \multirow[t]{7}{*}{$\mathrm{U}$} & $\mathrm{w}(\{1\})$ & 4900 & 0 & 0 \\
\hline & $\mathrm{w}(\{2\})$ & 4180 & 0 & 0 \\
\hline & $\mathrm{w}(\{3\})$ & 5560 & 0 & 0 \\
\hline & $\mathrm{w}(\{1,2\})$ & 10,025 & 945 & 0.09 \\
\hline & $\mathrm{w}(\{1,3\})$ & 14,055 & 3595 & 0.26 \\
\hline & $\mathrm{w}(\{2,3\})$ & 10,250 & 510 & 0.05 \\
\hline & $\mathrm{w}(\{1,2,3\})$ & 16,430 & 1790 & 0.11 \\
\hline
\end{tabular}

is an imputation vector for revenue sharing assignment if it ensures the individual rationality and efficiency conditions, i.e. $z_{i} \geq w(i)$ for all $i \in N$ and $\sum_{i=1}^{n} z_{i}=w(N)$, respectively. An imputation vector defines how $w(N)$ should be shared among the airlines (i.e. the players) in a way that no one declines the shared assignment. The whole imputation set for the cooperative game is defined as $=\left\{\vec{z}=\left(z_{1}, z_{2}, \ldots, z_{n}\right) \mid z_{i} \geq w(i), \sum_{i=1}^{n} z_{i}=w(N)\right\}$. The purpose of cooperative game theoretical solution concepts is to assign a fair revenue sharing amount among the players. In this regard, various cooperative game theoretical methods have been suggested in the scientific literature (Lozano et al. 2013; Hafezalkotob et al. 2019). For the imputation of $\vec{z} \in Z$, the satisfaction of a coaliton $S \in N$ is expressed as $e(S, z)=w(S)-\sum_{i \in S} z_{i}$. This indicates that the value of the revenue sharing assigned to the coalition $S$ varies from the revenue associated with $S$. Another cooperative game theoretical solution concept is the core, which is defined as a set all of the feasible imputations. The core provides set-valued solution concepts that cannot be improved by any coalition. If the core of a cooperative game is non-empty, the game is also called stable (Gillies 1959). The core of any cooperative game $w$ is defined as 
follows:

$$
\operatorname{Core}(w)=\{\vec{z} \in Z \mid e(S, \vec{z}) \leq 0, \forall S \subset N\}=\left\{\vec{z} \in Z \mid w(S) \leq \sum_{i=1}^{N} z_{i}, \forall S \subset N\right\}
$$

Although the core solution concept is set-valued, the $\varepsilon-$ Core (Mini-MaxCore) is a single valued solution concept. Moreover, $\varepsilon-$ Core completely avoids the solution space from each side of the borders until a single point solution exists. $\varepsilon-$ Core can be obtained with the following mathematical programming model (Maschler et al., 1979):

$\min \varepsilon$

\section{Subject to}

$$
e(S, \vec{z})=w(S)-\sum_{i \in S} z_{i} \leq \varepsilon, \forall S \subset N, S \neq N
$$

The Shapley value can be used when calculating the revenue sharing amount. This value shows how much the airlines benefit if they form a coalition. This is based on the average contributions of the players (airlines) and provides efficiency, symmetry, additivity, and dummy player properties. An imputation vector $\vec{z}=\left(z_{1}, z_{2}, \ldots, z_{n}\right)$ indicates the Shapley value for the players as follows:

$$
z_{i}=\sum_{S \subset \pi^{i}}[w(S)-w(S-\{i\})] \frac{(|S|-1) !(N-|S|) !}{N !}, i=\{1,2, \ldots, n\} .
$$

Here, $\pi^{i}$ is the permutations of all coalition $S \subset N$, covering player $i$ as a member, and $|S|$ shows the number of alliance members in $S$ (Shapley 1952).

A new revenue sharing concept was also examined that minimizes the maximum variety in the mutual relative revenue of the players. It was introduced as the equal revenue method and was inspired by Audy et al. (2012). The ERM is formulated as follows:

$\min t$

\section{Subject to}

$$
\begin{gathered}
t \geq \frac{z_{i}}{w(i)}-\frac{z_{j}}{w(j)}, \forall(i, j) \in N \\
\sum_{i \in S} z_{i} \geq w(S), \forall S \subset N, S \neq N
\end{gathered}
$$




$$
\sum_{i \in N} z_{i}=w(N)
$$

The $t$ variable quantifies the maximum diversity between the revenue sharing assignments. Constraint (13) evaluates the diversity among the relative revenue sharing amounts of the players. Constraint (14) represents the group rationality constraint, where none of the airlines are allocated lower than if they withdraw from the grand coalition, and Constraint (15) guarantees the efficiency that all of the generated revenue is distributed.

Another solution concept for the revenue sharing of cooperative game theory is the Nucleolus solution (Schmeidler 1969). The aim of the Nucleolus solution concept is minimizing the maximum dissatisfaction level of any coalitions. If the core is nonempty, the nucleolus belongs to the core, and it expresses stable revenue sharing. The Nucleolus solution is formulated as follows:

$\max e$

$$
\begin{gathered}
e+\sum_{i \in S} z_{i} \leq w(S) \forall S \subset N, S \neq \emptyset \\
\sum_{i \in N} z_{i}=w(N) \\
e \in \mathbb{R}, z_{i} \in \mathbb{R} \forall i \in N
\end{gathered}
$$

The objective function minimizes the maximum dissatisfaction level $e$. The restrictions given in Eq. (17) show that this $e$ cannot be less than the dissatisfaction of any coalition. In addition, Eqs. (16) and (17) are used together to ensure that $e$ is equal to the minimum dissatisfaction value. Constraint (18) is the efficiency condition that ensures that the grand coalition $w(N)$ value is obtained from all of the coalition values. Equation (19) shows the structure of the variables used in the model.

In the three cases, the $\mathrm{L}, \mathrm{W}$, and $\mathrm{U}$ for the imputations were obtained by different cooperative game concepts and are illustrated in Table 6, which include the Shapley value, equal revenue method, Nucleolus, and minimax core. The case results of the Shapley value and Nucleolus were calculated using the CoopGame package with R programming language (Staudacher and Anwande 2019). However, the Gams 14 solver was used to calculate the results of the ERM and the minimax core problem.

From Table 6, it can be seen that for case W, the Shapley value and Nucleolus method results were almost similar to the other methods and the cases came up with rather different results. Moreover, calculating the ERM method in cases $\mathrm{L}$ and $\mathrm{U}$ was not possible because the game had an empty core.

The imputation sets, and corresponding cores in the barycentric coordinates, are graphically demonstrated in Fig. 2. Here, the corresponding red shaded area indicates the core of W. Furthermore, the imputation vertices are given for cases L and U, since they had empty cores. If the game is convex, its core touches all three sides of the 
Table 6 Revenue sharing imputations of the different cooperative game theoretical concepts

\begin{tabular}{llllll}
\hline Case & Airlines & Shapley value & ERM & Nucleolus & Minimax core \\
\hline L & $\{1\}$ & 5600.83 & - & 5542.50 & 5281.67 \\
& $\{2\}$ & 4128.33 & - & 4040.00 & 4971.67 \\
& $\{3\}$ & 5805.34 & - & 5952.50 & 5281.67 \\
& Stable & No & - & No & No \\
W & $\{1\}$ & 5371.67 & 5283.29 & 5386.25 & 5357.50 \\
& $\{2\}$ & 4916.67 & 4772.38 & 4916.25 & 4887.50 \\
& $\{3\}$ & 5886.67 & 6119.33 & 5872.50 & 5930.50 \\
& Stable & Yes & Yes & Yes & Yes \\
U & $\{1\}$ & 6083.34 & - & 6012.50 & 5540.00 \\
& $\{2\}$ & 3820.83 & - & 4180.00 & 4690.00 \\
& $\{3\}$ & 6525.83 & - & 6237.50 & 6200.00 \\
& No & No & - & No & No \\
\hline
\end{tabular}

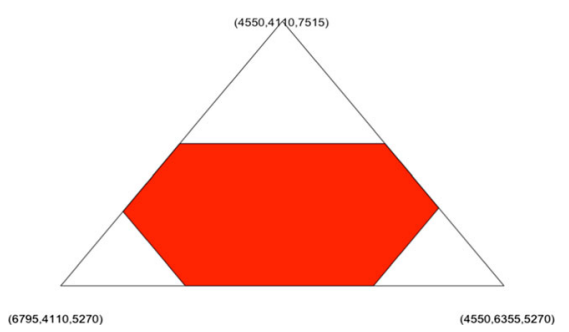

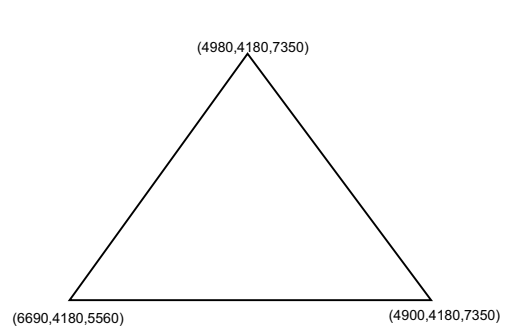

Case U

\section{Case W}

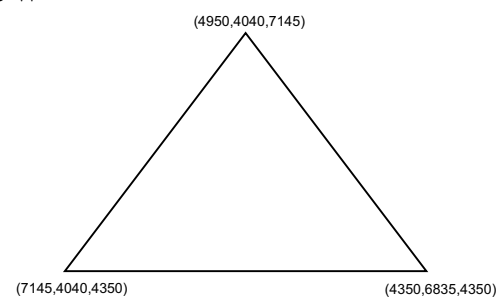

Case L

Fig. 2 Core of the collaborative grey game model for the three different cases

imputation triangle. Therefore, the game corresponding to case $\mathrm{W}$ was convex (see Fig. 2).

Satisfaction of coalition $S$ from the imputation $\vec{z}=\left(z_{1}, z_{2}, \ldots, z_{n}\right)$, is expressed as the difference between the shared revenue obtained from grand coalition and the revenue if coalition $S$ operates individually, that is, $F(S, \vec{z})=\sum_{i \in S} z_{i}-w(S)=$ 
$-e(S, z)$. Table 7 demonstrates the corresponding satisfaction values $F(S, \vec{z})$ for each coalition and the relative values $F(S, \vec{z}) / w(S)$. It can be seen in Table 6 that the relative satisfaction values of the coalitions decrease as the coalitions grow. That is, as the coalition becomes larger, the benefits to be obtained from adding a new airline are reduced. In real cases, these benefits may not outweigh the complexity involved in collaboration of the airline alliance.

Table 7 Coalition satisfactions for different cooperative game theoretical solution concepts

\begin{tabular}{|c|c|c|c|c|c|}
\hline Case & Coalition & Shapley & ERM & Nucleolus & $\begin{array}{l}\text { Minimax } \\
\text { Core }\end{array}$ \\
\hline \multirow[t]{6}{*}{$\mathrm{L}$} & $\mathrm{w}(\{1\})$ & $1250.83(29 \%)$ & & $1192.50(27 \%)$ & $\begin{array}{r}931.67 \\
(21 \%)\end{array}$ \\
\hline & $\mathrm{w}(\{2\})$ & $88.33(2 \%)$ & & $0.00(0 \%)$ & $\begin{array}{r}931.67 \\
(23 \%)\end{array}$ \\
\hline & $\mathrm{w}(\{3\})$ & $1455.34(33 \%)$ & & $1602.50(37 \%)$ & $\begin{array}{r}931.67 \\
(21 \%)\end{array}$ \\
\hline & $\mathrm{w}(\{1,2\})$ & $369.17(4 \%)$ & & $222.50(2 \%)$ & $\begin{array}{l}893.33 \\
(10 \%)\end{array}$ \\
\hline & $\mathrm{w}(\{1,3\})$ & $\begin{array}{r}-998.83 \\
(-8 \%)\end{array}$ & & $\begin{array}{r}-910.00 \\
(-7 \%)\end{array}$ & $\begin{array}{r}-1841.67 \\
(-15 \%)\end{array}$ \\
\hline & $\mathrm{w}(\{2,3\})$ & $163.67(2 \%)$ & & $222.50(2 \%)$ & $\begin{array}{r}483.32 \\
(5 \%)\end{array}$ \\
\hline \multirow[t]{6}{*}{ W } & $\mathrm{w}(\{1\})$ & $821.67(18 \%)$ & $733.29(16 \%)$ & $836.25(18 \%)$ & $\begin{array}{r}807.50 \\
(17 \%)\end{array}$ \\
\hline & $\mathrm{w}(\{2\})$ & $806.67(20 \%)$ & $662.38(1 \%)$ & $806.25(19 \%)$ & $\begin{array}{r}777.50 \\
(19 \%)\end{array}$ \\
\hline & $\mathrm{w}(\{3\})$ & $616.67(11 \%)$ & $849.32(16 \%)$ & $602.50(12 \%)$ & $\begin{array}{r}660.50 \\
(12 \%)\end{array}$ \\
\hline & $\mathrm{w}(\{1,2\})$ & $588.34(6 \%)$ & $355.67(4 \%)$ & $602.50(6 \%)$ & $\begin{array}{r}545.00 \\
(6 \%)\end{array}$ \\
\hline & $\mathrm{w}(\{1,3\})$ & $778.34(7 \%)$ & $922.61(9 \%)$ & $778.75(7 \%)$ & $\begin{array}{r}808.00 \\
(7 \%)\end{array}$ \\
\hline & $\mathrm{w}(\{2,3\})$ & $793.34(8 \%)$ & $881.70(9 \%)$ & $778.75(8 \%)$ & $\begin{array}{r}808.00 \\
(8 \%)\end{array}$ \\
\hline \multirow[t]{6}{*}{$\mathrm{U}$} & $\mathrm{w}(\{1\})$ & $1183.33(24 \%)$ & & $1112.50(23 \%)$ & $\begin{array}{r}640.00 \\
(13 \%)\end{array}$ \\
\hline & $\mathrm{w}(\{2\})$ & $\begin{array}{r}-359.17 \\
(-9 \%)\end{array}$ & & $0.00(0 \%)$ & $\begin{array}{r}510.00 \\
\quad(12 \%)\end{array}$ \\
\hline & $\mathrm{w}(\{3\})$ & $965.83(17 \%)$ & & $677.50(12 \%)$ & $\begin{array}{r}640.00 \\
(12 \%)\end{array}$ \\
\hline & $\mathrm{w}(\{1,2\})$ & $\begin{array}{r}-120.83 \\
(-1 \%)\end{array}$ & & $167.50(2 \%)$ & $\begin{array}{r}205.00 \\
(2 \%)\end{array}$ \\
\hline & $\mathrm{w}(\{1,3\})$ & $\begin{array}{r}-1445.83 \\
(-10 \%)\end{array}$ & & $\begin{array}{r}-1805.00 \\
(-13 \%)\end{array}$ & $\begin{array}{r}-2315.00 \\
(-16 \%)\end{array}$ \\
\hline & $\mathrm{w}(\{2,3\})$ & $96.67(9 \%)$ & & $167.50(2 \%)$ & $\begin{array}{r}640.00 \\
(6 \%)\end{array}$ \\
\hline
\end{tabular}



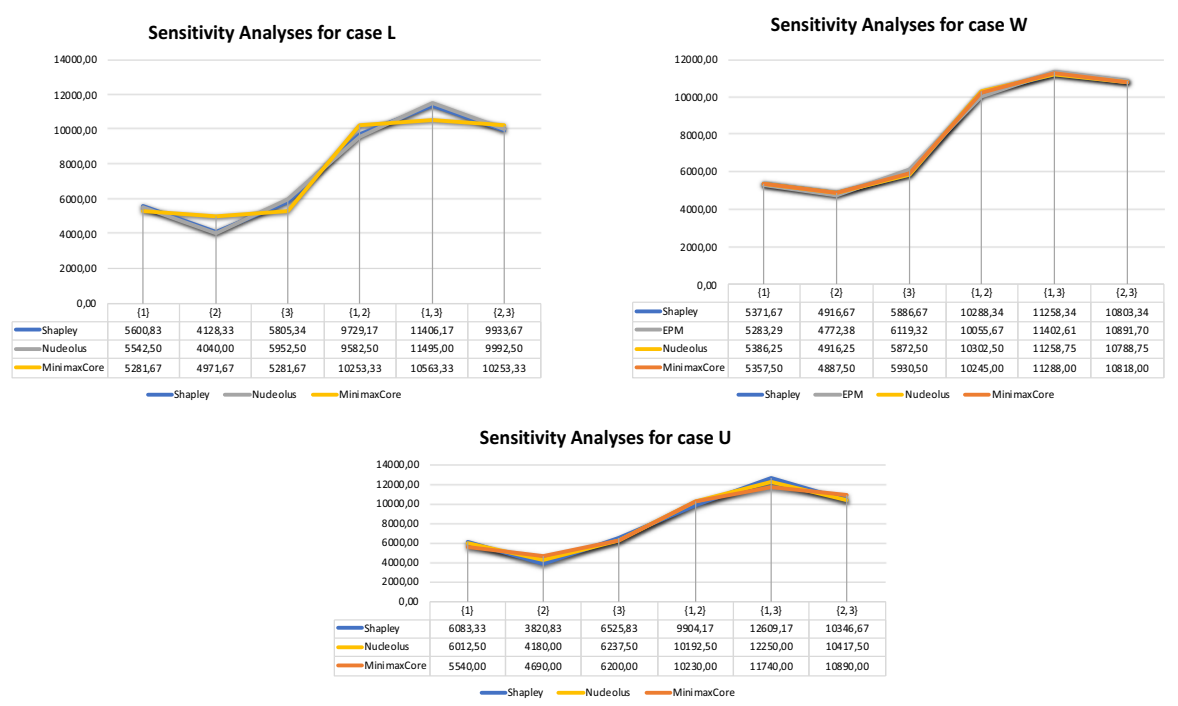

Fig. 3 Sensitivity analyses for all of the cases

Table 7 illustrates that the number of airlines increased in a coalition in of all the cases, and the obtained benefits decreased due to adding new airlines. Furthermore, the coalition satisfactions in case $\mathrm{W}$ were often higher than in the other cases. Thus, in this example, when the airline collaborations had lower and upper demands, the willingness of the airlines to form the collaboration decreased. Moreover, cases L, U, and the coalitions (see $w\{1,3\}$ coalition for case $\operatorname{L}$ and $w\{2\}, w\{1,2\}, w\{1,3\}$ coalitions for case $U$ ) were not satisfied with the sharing revenue in the Shapley value, Nucleolus, or minimax core method, and the games, were not stable. Figure 3 demonstrates the sensitivity analyses of all of the cases of the cooperative game methods. According to the sensitivity analysis, it was determined that the maximum revenue sharing for all of the cases resulting from the coalitions were distributed to airline 3 and the minimum was distributed to airline 2 following all of the sharing methods.

The mean absolute deviation (MAD) between the revenue sharing was calculated to find the dissimilarity between the four cooperative game theoretical solution concepts for case W. The MAD quantify for two imputations, $\vec{z}=\left(z_{1}, z_{2}, \ldots, z_{n}\right)$ and $\overrightarrow{z^{\prime}}=$ $\left(z_{1}^{\prime}, z_{2}^{\prime}, \ldots, z_{n}^{\prime}\right)$, was calculated by:

$$
M A D=\left(z, z^{\prime}\right)=\frac{|N|}{w(N)} \sum_{i}\left|z_{i}-z_{i}^{\prime}\right|
$$

Table 8 shows the MAD values for each pair of the cooperative game theoretical solution concepts. It is shown that the solution concepts of cooperative game theory were not generally similar. The results showed that the Shapley value, Nucleolus, and minimax provided almost similar performance, while the ERM method was dissimilar.

The results of the numerical example provided the following managerial insights: 
Table 8 Similarity between the solution concepts calculated by the MAD values for case W

\begin{tabular}{lllll}
\hline Solution concept & Shapley value & ERM & Nucleolus & Minimax core \\
\hline Shapley Value & - & 0.62 & 0.04 & 0.12 \\
ERM & & - & 0.66 & 0.51 \\
Nucleolus & & - & 0.15 \\
Minimax Core & & & - \\
\hline
\end{tabular}

- The cooperative game theoretical solution concepts provided useful tools and shared the extra revenues from the collaboration of the airlines. The solution concepts of the cooperative game theory helped to choose the best revenue sharing system to maximize the airlines' satisfaction. Moreover, the fair and stable extra revenues promoted the continuance of their alliance in case $\mathrm{W}$.

- Different cooperative game theory sharing methods generated revenue sharing distributions supported by various interpretations of fairness. These sharing distributions were basically based on the contributions of aid airlines in their coalitions with others.

\section{Conclusion and further research}

Most of the research on traditional airline alliance revenue management has just analyzed the airline alliance revenue sharing problem under a certain situation. This study presented a new GMP model for the airline alliance revenue sharing problem with the grey demand arriving at the airlines. Furthermore, the extra revenues of such a collaboration were calculated among different airline companies. This study practically examined several collaborative game theoretical solution methods, including the Shapley value, equal revenue, Nucleolus, and minimax core method on a numerical example. It is known that the potential of extra revenues of collaborations and super additive property are contingent upon the demand structure of the coalitions, such as in cases $\mathrm{L}, \mathrm{W}$, and $\mathrm{H}$. It was determined herein that the synergy of the collaboration increased with the size of coalition in all of the cases. However, in cases $\mathrm{L}$ and $\mathrm{U}$, the game was not super additive.

The limitations of this paper included the fact that other uncertainty approaches, such as parallelepiped uncertainty (Kara et al. 2019), semialgebraic uncertainty (Kropat et al. 2020), interval uncertainty (Ergun et al. 2020), robust optimization (Goli et al. 2019; Tirkolaee et al. 2020), fuzzy uncertainty (Goli and Malmir 2020; Goli et al. 2021), and metaheuristic approaches (Goli et al. 2018; Pahlevan et al. 2021) were not developed and compared to the current GMP approach. There are various directions and suggestions for further research. First, in the real world, the number of airline alliance members may become large-sized and studying the effects of revenue sharing in different large-sized alliances on the collaboration of airlines would be extremely interesting. Second, developing the suggested model to investigate other additional 
costs for the airlines is an interesting extension. Finally, this paper did not consider a cooperative fuzzy game theoretic scenario-based planning model. Moreover, considering the different risk levels and sensitivities of airline revenues that would result in a collaborative game model under uncertain conditions would be challenging.

Funding The author received no financial support for the research, authorship, or publication of this article.

\section{References}

Alparslan-Gök SZ, Palancı O, Yücesan Z (2018) Peer group situations and games with grey uncertainty. In: Vasant P, Alparslan-Gok SZ, Weber G (eds) Handbook of Research on Emergent Applications of Optimization Algorithms. IGI Global, pp 265-278

Agarwal R, Ergun O, Houghtalen L, Ozener OO (2009) Collaboration in cargo transportation In Optimization and logistics challenges in the enterprise. Springer, Berlin

An Q, Wen Y, Ding T, Li Y (2019) Resource sharing and payoff allocation in a three-stage system: integrating network DEA with the Shapley value method. Omega (United Kingdom) 85:16-25

Audy JF, D’Amours S, Rönnqvist M (2012) An empirical study on coalition formation and cost/savings allocation. Int J Prod Econ 136:13-27

Benítez RBC, Paredes RBC, Lodewijks G, Nabais JL (2013) Damp trend grey model forecasting method for airline industry. Expert Syst Appl 40(12):4915-4921

Chung KH, Ko SY, Ko CS (2018) Collaborative and Sustainable Network Design in Courier Services IFIP International Conference on Advances in Production Management Systems (pp 254-261) Springer, Cham

Cetiner D, Kimms A (2013) Assessing fairness of selfish revenue sharing mechanisms for airline alliances. Omega (United Kingdom) 41:641-652

Ergün S, Kırlar BB, Gök SZA, Weber GW (2020) An application of crypto cloud computing in social networks by cooperative game theory. J Indus Manag Optim 16(4):1927

Frisk M, Göthe-Lundgren M, Jörnsten K, Rönnqvist M (2010) Cost allocation in collaborative forest transportation. Eur J Oper Res 205:448-458

Gillies DB (1959) Solutions to general non-zero-sum games. Contrib Theory Games 4:47-85

Goli A, Zare HK, Moghaddam R, Sadeghieh A (2018) A comprehensive model of demand prediction based on hybrid artificial intelligence and metaheuristic algorithms: A case study in dairy industry

Goli A, Malmir B (2020) A covering tour approach for disaster relief locating and routing with fuzzy demand. Int J Intell Transp Syst Res 18(1):140-152

Goli A, Tirkolaee EB, Aydin NS (2021) Fuzzy integrated cell formation and production scheduling considering automated guided vehicles and human factors. IEEE Transactions on Fuzzy Systems

Goli A, Zare HK, Tavakkoli-Moghaddam R, Sadeghieh A (2019) Application of robust optimization for a product portfolio problem using an invasive weed optimization algorithm. Numer Algebra, Control Optim 9(2):187

Grauberger W, Kimms A (2016) Revenue management under horizontal and vertical competition within airline alliances. Omega (United Kingdom) 59:228-237

Gu YJ, Zhu JF (2017). Capacity Allocation and Revenue Sharing in Airline Alliances: A Combinatorial Auction-Based Modeling. Mathematical Problems in Engineering 2017

Hafezalkotob A, Chaharbaghi S, Lakeh TM (2019) Cooperative aggregate production planning: a game theory approach. J Indus Eng Int 15:19-37

Hafezalkotob A, Khodabakhsh M, Saghaei A, Eshghipour M (2018) Cooperation of advertising companies in social networks: a graph and game theory approaches. Comput Ind Eng 125:212-220

Hafezalkotob A, Makui A (2015) Cooperative maximum-flow problem under uncertainty in logistic networks. Appl Math Comput 250:593-604

Houghtalen L, Ergun Ö, Sokol J (2011) Designing mechanisms for the management of carrier alliances. Transp Sci 45:465-482

Hsu CI, Wen YH (2000) Application of grey theory and multiobjective programming towards airline network design. Eur J Oper Res 127(1):44-68 
Hu X, Caldentey R, Vulcano G (2013) Revenue sharing in airline alliances. Manage Sci 59(5):1177-1195

Joanna M, Marek G, Władysław M (2020) The concept of the qualitology and grey system theory application in marketing information quality cognition and assessment. CEJOR 28(2):817-840

Julong D (1982) Grey control system. J Huazhong Univ Sci Technol 3(9):18

Julong D (1989) Introduction to grey system theory. J Grey Syst 1(1):1-24

Kara G, Özmen A, Weber GW (2019) Stability advances in robust portfolio optimization under parallelepiped uncertainty. CEJOR 27(1):241-261

Kimms A, Cetiner D (2012) Approximate nucleolus-based revenue sharing in airline alliances. Eur J Oper Res 220:510-521

Krajewska MA, Kopfer H, Laporte G, Ropke S, Zaccour G (2008) Horizontal cooperation among freight carriers: request allocation and profit sharing. J Op Res Soc 59(11):1483-1491

Kropat E, Weber GW, Tirkolaee EB (2020) Foundations of semialgebraic gene-environment networks. J Dyn Games 7(4):253

Levi R, Perakis G, Shi C, Sun W (2020) Strategic capacity planning problems in revenue-sharing joint ventures. Prod Oper Manag 29(3):664-687

Li T, Xie J, Lu S, Tang J (2016) Duopoly game of callable products in airline revenue management. Eur J Oper Res 254(3):925-934

Liu S, Forrest JYL (2010) Grey systems: theory and applications. Springer, Berlin

Liu M, Hou Y, Chu F, Huo J (2017) Revenue management of airline alliances with integral planning strategy. In 2017 International Conference on Service Systems and Service Management (pp. 1-6). IEEE

Liu W, Yang W, Zhu X (2014) Cooperative game study of airlines based on flight frequency optimization. J Appl Math 2014:1-5

Lozano S, Moreno P, Adenso-Díaz B, Algaba E (2013) Cooperative game theory approach to allocating benefits of horizontal cooperation. Eur J Oper Res 229:444-452

Mallozzi L, Scalzo V, Tijs S (2011) Fuzzy interval cooperative games. Fuzzy Sets Syst 165(1):98-105

Maschler M, Peleg B, Shapley LS (1979) Geometric properties of the kernel, nucleolus, and related solution concepts. Math Oper Res 4(4):303-338

Nerja A (2017) Effects of concession revenue sharing contracts and airline alliances in airport competition (No. 0317). University of Valencia, ERI-CES

Netessine S, Shumsky RA (2005) Revenue management games: horizontal and vertical competition. Manage Sci 51:813-831

Pahlevan SM, Hosseini SMS, Goli A (2021) Sustainable supply chain network design using products' life cycle in the aluminum industry. Environmental Science and Pollution Research, 1-25

Qin J, Wang K, Wang Z, Xia L (2020) Revenue sharing contracts for horizontal capacity sharing under competition. Ann Oper Res 291:731-760

Saraswati B, Hanaoka S (2014) Airport-airline cooperation under commercial revenue sharing agreements: a network approach. Transp Res Part e: Logist Transp Rev 70:17-33

Schmeidler D (1969) The nucleolus of a characteristic function game. SIAM J Appl Math 17(6):1163-1170

Seo G-H (2020) Competitive advantages of international airline alliances: a critical review. HOLISTICA J Bus Pub Adm 11:139-145

Shapley LS (1952) A value for n-person games (No. RAND-P-295). Rand Corp Santa Monica CA

Sorouri Ghare-Aghaj S, Sadeghian R, Tavakkoli-Moghaddam R, Makui A (2019) Introducing a framework for analyzing the cooperation of airlines by the game theory approach. Modern Res Decis Mak 4(1):78-99

Staudacher J, Anwander J (2019) Using the R package CoopGame for the analysis, solution and visualization of cooperative games with transferable utility; $\{\mathrm{R}\}$ Vignette; 2019

Sur M, Lee DJ, Kim KT (2019) Optimal revenue sharing in platform markets: a Stackelberg model. J Reven Pricing Manag 18:317-331

Tirkolaee EB, Mahdavi I, Esfahani MMS, Weber GW (2020) A robust green location-allocation-inventory problem to design an urban waste management system under uncertainty. Waste Manage 102:340-350

Wang Y (2020) Revenue sharing in airline alliance networks. Int Game Theory Rev 22(04):2050008

Wen YH (2017) Airline Cargo Alliance and Allied Flight Frequency Analysis using the Fuzzy Cooperative Game and Flight Frequency Programming. In 2017 6th IEEE International Conference on Advanced Logistics and Transport (ICALT) (pp 81-86). IEEE

Wright CP (2014) Decomposing airline alliances: A bid-price approach to revenue management with incomplete information sharing. J Reven Pricing Manage 13:164-182 
Zhang M, Fu Y, Zhao Z et al (2019) Game theoretic analysis of horizontal carrier coordination with revenue sharing in E-commerce logistics. Int J Prod Res 57:1524-1551

Publisher's Note Springer Nature remains neutral with regard to jurisdictional claims in published maps and institutional affiliations. 